\title{
Protection of right to reproduction in internet under copyright law
}

\begin{abstract}
Innovation and speed are the twin watchwords of a knowledge-based economy. The most astonishing feature of the emergence of new technologies is the enabling dissemination of knowledge in a hitherto unprecedented manner. These scientific break-through and technological developments through Internet have created a corresponding demand for strengthening the legal protection machinery. Situated against this backdrop, legal protection of copyright in Internet poses a singular range of legal issues. The article critically examines these advancements and their link with the law of copyright with special reference to the role of judiciary in the developing context of the India and USA.
\end{abstract}

Volume 6 Issue 5 - 2018

Jatindra Kumar Das

Department of Law, University of Calcutta, India

Correspondence: Jatindra Kumar Das, Department of Law, University of Calcutta, Kolkata-700019, India,Tel + 09231875059,Email dasjkdas@rediffmail.com

Received: September 27, 2018 | Published: October 25, 2018

\section{Introduction}

A close examination of clauses (a), (b) and (c) to Section 14 of the Copyright Act, 1957 shows that the right to reproduction constitutes only one of the bundles of rights accorded to a copyright owner of literary, dramatic, musical or artistic work. ${ }^{1}$ The "right to reproduction" is not given to the copyright owner of cinematograph films and sound recordings but the "right to make a copy" is given instead. The right to translation, right to adaptation, right to performance of work etc. also involves reproduction in the generic sense of the term. Whether this difference is justified? Whether right to reproduction is an umbrella right or a residuary right? In case of artistic work, Section 14(c) (i) gave the right to reproduce the work in any material form to the copyright owner but the right to store the work in any medium by electronic means was not given. ${ }^{2}$ The Copyright (Amendment) Act, 2012 has removed this lacuna and included storing of work in right of reproduction in case of artistic work also. However, in case of artistic works the right is elaborated to include depiction in three dimensions of a two dimensional work or in two dimensions of a three dimensional work. ${ }^{3}$ Again question arises whether right to reproduction in Internet is sufficiently protected under the post 2012 amended Copyright Act 1957. It is relevant to mention here that the Internet is the greatest communication medium of the contemporary era. It brings the whole world to a mouse click of a computer, making innumerable sources and references available in matter of seconds. ${ }^{4}$ Copyright protection is provided to the authors of "original works" of literary, dramatic, musical, artistic, and architectural and certain other intellectual works both published and unpublished ${ }^{5}$ while the Internet

${ }^{1}$ For various issues on copyright, see, Jatindra Kumar Das, Law of Copyright (PHI Learning, Delhi, 2015); J. K. Das, “The TRIPS Agreement and Intellectual Property Rights" 16 (6) International Trade Law and Regulation (Sweet and Maxwell, London, 2010) pp. 166-174; J. K. Das, Intellectual Property Rights (Kamal Law House, Kolkata, 2008).

${ }^{2}$ See Super Cassettes Industries Pvt. Ltd. v. Trimurti Films Pvt. Ltd., 2018 (1) Bom CR 156

${ }^{3}$ Inserted by the Copyright (Amendment) Act, 2012 [w. e. f. 21. 6. 2012 ] Section 14(c)(i).

${ }^{4}$ See Mark A. Lemley, Dealing with Overlapping Copyrights on the Internet, 224 Dayton Law Review (1997) pp. 547-555; Neal Kumar Katyal, "Criminal Law in Cyber-space" 149 University of Pennsylvania Law Review, (2001)pp. 1006-1013.

${ }^{5}$ See Myspace Inc. v. Super Cassettes Industries Ltd., 2017(69)PTC1(Del): has been characterized as the largest threat to copyright protection since its inception. ${ }^{6}$ The Internet is awash in information, a lot of it with varying degrees of copyright protection. Copyrighted works on the Internet include news stories, software, novels, screenplays, graphics, and pictures, use Internet messages and even email. In fact, the frightening reality is that almost everything on the Internet is protected by copyright law. That can pose problems for the hapless surfer. In a modern world where information is a key factor and the information is available with the click of a mouse on a computer from the Internet, it's an era of expansion. ${ }^{7}$ Internet is a medium which provides audio-visual interactive facility for doing business. Merely because it is a more advanced or superior medium, it does not impinge on the determination of the issue whether the merchandiser is carrying on business at a particular place. Prior to the advent of electronic commerce (e-commerce) over the Internet, and even now, business was and continues to be done over telephone and fax. Merely because a person has embarked upon an e-commerce business model, the tests which apply for determination of issues, such as-when and where the contract is made, or whether the vendor carries on business at the place where the merchandise may be sold, or service may be offered, would not change and would be the same as apply to communications over telephone and fax. ${ }^{8}$ In Yahoo, Inc v. Akash Arora, ${ }^{9}$ the Delhi High Court takes note of the transcendental nature of Internet business's wherein the Court observed that:

"As a matter of fact in a matter where services are rendered through the domain name in the Internet, a very alert vigil is necessary and a strict view is to be taken for its easy access and reach by anyone from any corner of the globe." Thus, one of the significant technological revolutions took place in the last century was the invention of digital

MIPR2017(1)274; Institute for Inner Studies v. Charlotte Anderson, MIPR 2014 (129) 1; Bayer Corporation v. Cipla, Union of India, MIPR 2009 (3) 467: 2009 (41) PTC 634 (Del); Syndicate of Press of the University of Cambridge v. Kasturi Lan, 2006 (32) PTC 487 (Del); McMillan and Co. Ltd. v. Kand J. Cooper, AIR 1924 PC 75: 1924 - 19 - LW 299.

${ }^{6}$ See Ejan Mackaay (ed.), The Electronic Superhighway: The Shape of Technology and Law to Come, (Kluwer Law International, 1995).

${ }^{7}$ Mrs. Ishi Khosla v. Anil Aggarwal, (2007) ILR 1 Delhi 615: 2007 (34) PTC 370 (Del)

${ }^{8}$ See J. H. Smith Grahm, Internet Law and Regulation (Sweet and Maxual, London, 2002).

${ }^{9} 1999$ (19) PTC 201: 78 (1999) DLT 285. 
technology. The emergence of Internet as a powerful and reliable platform for communication facilitated the creation of new works in the form of multimedia. Hence, these works are used not only for educational purposes but also for business. This led to the formation of new capital in the area of information creation and distribution for commercial gains in the global market, information technology industry is projected as one of the most powerful sources for capital formation and employment generation in the new century. The law relating to copyright proved to be one of the powerful legal instruments for the purpose of protecting capital investment in the area of cultural industries. It was also projected as a legal instrument that tried to maintain the delicate balance between the interest of owners of copyright and the general public. The traditional norms for the protection of copyright in the works were amended periodically to suit technological changes without sacrificing the public interest. ${ }^{10} \mathrm{It}$ has been argued that in the context of digital technology existing legal norms seem inadequate to solve the problems posed by this new technology. ${ }^{11}$ The most fundamental issues in the field of copyright and related rights are the determination of the scope and protection of rights of copyright owners in the digital era. ${ }^{12}$ Besides, the right of reproduction of an author is another controversial issue in the digital era. In the digital context the copyrighted works are stored in digital format and multiplied every time it is used or sent to another person.

In some cases like browsing of materials in the web, transmission of materials, providing access by linking etc., the works are reproduced for a short period of time. The users may also download and store the material in the computer for the purpose of using it at their convenience. They may also transmit it to others for personal use. The question that arises is whether all forms of reproduction, whether temporary or permanent, form part of reproduction right in the digital context. The creators of content for the digital are argue that all forms of reproduction whether temporary or permanent must be treated as reproduction even though there can be exception in some cases. On the other hand the users of the work and the providers of access to these materials assert that reproduction in permanent fond alone must be recognized as right of reproduction. ${ }^{13}$ The question is who will take the responsibility to monitor violations of rights in Internet? Can the providers of Internet service be held responsible for the violations that take place in the Internet of which he may or may not have any information? If so, to what extent? Do they have the responsibility to monitor the violation? Can they absolve the responsibility even if the violations are brought to their notice? Are their activities like providing access by linking including deep linking, system caching, framing etc. are violations of the right of reproduction? Similarly, is the question of the liability of the users of the Internet is controversial in the contemporary era. Are the activities of browsing, downloading, storing and transmitting of works for any non-commercial purposes violation of the rights? Is this to be treated as fair use or use with implied licence? How the right of authors should be defined and what

${ }^{10}$ See, the amendments introduced to the Copyright Act, 1957 in 1984, 1994, 1999 and 2012

${ }^{11}$ See Sinday A. Rosenzweig, "Don't Put My Article Online: Existing Copyright's New-use Doctrine to the Electronic Publishing Media and Beyond", 143 University of Pennsylvania Law Review, 639 (1994-95).

${ }^{12} \mathrm{See}$, Binu Poornamodan Cholayil, "Digital Rights Management and Fair Use in Copyright Law" 33(1-2) Cochin University Law Review (2009) p. 166.

${ }^{13}$ See Nandan Kamat, Law Relating to Computers Internet and E-Commerce, (Universal Law Publishing Co., New Delhi, 2012). exceptions and limitations are to be permitted to such rights? How are the rights of authors to be enforced and administered in this digital environment? Can the existing worldwide copyrights law adequately protect the interests of those who hold copyright or are changes to the existing rules required? These questions need detail deliberation.

\section{Right of reproduction in internet}

\section{The concept}

Copyright protects the creative works of the copyright owner. Thus, according to Section 14 of the Copyright Act 1957, reproduction of creative works of copyright owner is a right in any material form which includes reproduction in Internet. It is a matter of fact that one of the important copyright implications by the transmission and use of works on the Internet is the exclusive right of reproduction of the author i. e. "to reproduce the work in any material form including the storing of it in any medium by electronic means." 14 Section 14 of the Copyright Act, 1957 states that copyright is an exclusive right, subject to the provisions of the Act, to do or authorize the doing of the acts enumerated in the said section, in respect of a work or any substantial part thereof. The Act provides for the "the exclusive rights flowing from such ownership as set out in Section 14." ${ }^{\prime 15}$ Further, under Section 14(i) (a) and (e) the right of reproduction of a literary, dramatic, musical work, sounds recording in any medium by electronic means are recognized. The concept of reproduction has been discussed in the House of Lords decision of Ladbroke (Football) Ltd. v. William Hill (Football) $L t d .{ }^{16}$ In this case the court held that copyright gives the exclusive right to do certain things including "reproducing the work in any material form", and reproduction includes reproduction of a substantial part of the work. Explaining the meaning of reproduction the court further observed:

Broadly, reproduction means copying, and does not include cases where an author or compiler produces a substantially similar result by independent work without copying. And, if he does copy, the question whether he has copied a substantial part depends much more on the quality than on the quantity of what he has taken. One test may be whether the part which he has taken is novel or striking, or is merely a commonplace arrangement of ordinary words or well-known data. So it may sometimes be a convenient short cut to ask whether the part taken could by itself be the subject of copyright. But, in my view, that is only a short cut, and the more correct approach is first to determine whether the plaintiffs' work as a whole is "original" and protected by copyright, and then to inquire whether the part taken by the defendant is substantial. Thus, even a substantial reproduction of a copyrighted work is sufficient to make it a copy. ${ }^{17}$ The Delhi High Court in Escorts Construction Equipment Ltd. v. Action Construction Equipment Pvt. $L t d .,^{18}$ held that a reproduction is also deemed to have taken place if there is substantial copying of an earlier work. In Mohendra Chandra

${ }^{14}$ Copyright Act, 1957, Section 14(i) (a) and (e). See Rediff.Com India Ltd. v. E-Eighteen.Com Ltd., MIPR 2013 (2) 333: 2013 (55) PTC 294 (Del).

${ }^{15}$ See Weider Publications v. Shri Pushpendra Srivastav, 20131 AD (Delhi) 501: 2013 (53) PTC 275 (Del).

${ }^{16}[1964] 1$ All E.R. 465: (1964) 108 S.J. 135.

${ }^{17}$ Keld Ellentoft India (P)Ltd. v. KE Burgmann, 2003 (26) PTC 541 (Del). See Achla Sabharwal v. National Film Development Corp. Ltd., 2017 XAD (Delhi) 287.

${ }^{18}$ AIR 1999 Del. 73. 
v. Emperor,${ }^{19}$ the Calcutta High Court has clarified that which comes to near the original, as to suggest that original to the mind of every person seeing it. Thus, there is no reproduction if there is no copying of the works and the defendant makes his own version, or goes to the common source if any.

It appears from the above discussion that the right of reproduction is one of the basic rights available to a copyright owner. To reproduce means to produces again, to produce a copy. It is the action or process of bringing again before the mind in the same form. In this sense even storage of the work in electronic means such as floppy discs, CDROMs or in computers shall be deemed to be a reproduction. This has been incorporated to guard the interest of right holders in the digital context. In the case of cinematograph films and sound recordings, the definition clause itself brings digital fixations within the scope of reproduction. But the term storage has not been defined. There is a possibility of including temporary storage also within reproduction right. This may create problems for the Internet users and service providers there by tilting the traditional balance of copyright law. Again, the right of reproduction is at the core of Internet activity because any transmission of a work or an object of related rights pre-supposes the upholding of that work or object into memory of a computer or other digital device. In addition, when the work is the transmitted over networks, multiple copies are made in the memory of computers in the networks at numerous points. "Copies" in the digital environment are something else than what they are in the case of printed word. For example, a node computer may receive only a few packets of the total data, the other packets being passed through a different route and therefore a different node computer's RAM. Whether the law considers these partial images a "copy" of the work? How can interim partial images of data stored in RAM be deemed a "copy" of a work, in the case where there is no point in time at which the entire work is available in a single RAM? It is therefore necessary to examine how the right of reproduction of authors is infringed by making of such copies by different computers in the network and others who access such works.

In Star India Pvt. Ltd. v. Roy $M A,{ }^{20}$ plaintiffs are leading sports broadcaster in India and the exclusive licensee of media rights to various sporting events / properties. They are also the owners of a network of sports television channels and by virtue of necessary downlink permissions from the Ministry of Information and Broadcasting. The plaintiffs alleged that the defendant's websites carry infringing content. It is also alleged that a Uniform Resource Locator (URL) at which the cricket matches are available for viewing on the plaintiffs website is http://starsports.com/cricket/index. In order to protect and enforce its exclusive rights, the plaintiffs engaged the services of a third party agency to monitor websites and gather evidence of their infringing activity. After carefully monitoring the activities of various websites for the past 3 (three) events for which the plaintiffs had exclusive rights, and in light of the evidence gathered against such websites, a list of 150 (one hundred and fifty) "Rogue Websites" has been prepared, whose primary business model appears to be providing illegal content for viewing and download. The court held that the plaintiffs have been able to make out a strong prima facie case for grant of ex-parte order. The balance of convenience also lies in favour of the plaintiffs and against the defendants. In case the interim orders are not passed, the plaintiffs would suffer irreparable loss and injury. In ad-interim orders the court restrained defendant from hosting,

\section{${ }^{19}$ AIR 1928 Cal.359.}

${ }^{20} 2014$ LawSuit (Del) 4442. streaming, broadcasting, rebroadcasting, retransmitting, exhibiting, making available for viewing and downloading, providing access to and / or communicating to the public, (including to its subscribers and users), through the internet, in any manner whatsoever, the plaintiffs' broadcast.

\section{International protection}

The international law had no occasion to address the protection of rights in internet till recently. This is evident from the fact that the TRIPS Agreement has no provision to solve these problems. ${ }^{21}$ Even though there was the possibility to interpret Article 9 of the Berne Convention dealing with reproduction right in the digital environment, there was considerable opposition having regard to the background in which this Article was introduced in Berne. ${ }^{22}$ There is also no provision in the Berne Convention capable of interpretation that can afford protection to the communication to public or publications right of the author in digital context. Needless to say that there is hardly any provision to enforce the rights. The TRIPS Agreement even though dealt with general provisions dealing with enforcement of rights, the issue of protecting technological measures used to protect digital materials was not addressed. These issues for the first time caught the attention of the international community in the WIPO Copyright Treaty, 1996 (WCT). ${ }^{23}$ Though there was general agreement among nations to protect communication to public right there were serious objections regarding the nature; and extend of reproduction right in digital format. The right of making available to the public the work in such a way that the members of the public may access the work form a place and at a time individually chose by them was incorporated in the WCT to cover the internet/online communication of the works. ${ }^{24}$ It was further made clear that providing mere physical facilities for enabling or making a communication does not in itself amount to communication with the meaning of this provision. This is to ensure protection for the service providers who provide mere physical facilities for internet communication. Since there was no agreement to treat both temporary and permanent reproduction as part of reproduction right in digital format, no specific provision was included in the WCT in this regard. But considering the importance of this right in the digital context it was agreed to extend Article 9 of Berne Convention to digital environment and expressly stated that

${ }^{21}$ Agreement on Trade-Related Aspects of Intellectual Property Rights, Marrakech, April 15, 1994, came into force January, 1 1995. Membership in TRIPS Agreement coincides with membership in the World Trade Organization except for least developed countries, which were granted a grace period; observer governments of the World Trade Organization are marked observer in the table below. India ratified it on January 1, 1995.

${ }^{22}$ Berne Convention for the Protection of Literary and Artistic Works, Berne, September 9, 1886, came into force on December 5, 1887. India ratified on April 1, 1928. For the text of the Convention, see, Alfredo Ilardiand and Michael Blakency, International Encyclopedia of Intellectual Property Treaties (Oxford University Press, 2004). The leading works on Berne Convention are, Ricketson, The Berne Convention for the Protection of literary and Artistic Works: 1886-1986 (1987); Nordemann, International Copyright and Neighbouring Rights Law (1990); Nimmer and Geller, International Copyright Law and Practice (1988).

${ }^{23}$ WIPO Copyright Treaty, Geneva, December 20, 1996, came into force March 6 , 2002. India has not ratified so far. See R.V. Vaidyanatha Ayyar, "Interest or Right? The Process and Politics of a Diplomatic Conference on Copyright," Journal of World Intellectual Property (1998) p. 3; Jorg Reinbothe, Maria Martin-Part and Silke Von Lewinski, "The New WIPO Treaties: A First Resume," 19 European International Property Report (1997) p. 171.

${ }^{24}$ See, Zakir Thomas, "Overview of Changes to the Indian Copyright Law", 17 Journal of Intellectual Property Rights (2012) pp. 324-334. 
storage of works in digital form would constitute reproduction as understood in Berne. Agreed statement concerning Article 1(4) read:

"The reproduction right, as set out in Article 9 of the Berne Convention, and the exceptions permitted there under, fully apply in the digital environment, in particular to the use of works in digital form. It is understood that the storage of protected work in digital form in an electronic medium constitutes a reproduction within the meaning of Article 9 of the Berne Convention”.

It was the failure of the international community due to the pressure form interest groups to reach consensus on the nature of the liability of service providers and users that lead this situation. This left the international norms regarding the rights of users of digital materials and the liability of the service providers unsettled. But it was agreed that all the exceptions and limitations recognized under the Berne Convention would be applicable to digital materials as well. ${ }^{25}$ This gives freedom to nations to introduce appropriate provision in their domestic law to protect the interest of the users and service providers without sacrificing the interest of the owners. This will lead to different types of norms followed by different countries for a technology that has no territoriality putting the content providers and service providers into difficulties. One of the major achievements of WCT is the provision regarding protection of right. It is obligatory on the part of nations to take adequate measures to protect the technological measures ${ }^{26}$ and right management system..$^{27}$ Article 12 of the WCT provides thus:

Contracting Parties shall provide adequate and effective legal remedies against any person knowingly performing any of the following acts knowing, or with respect to civil remedies having reasonable grounds to know, that it will induce, enable, facilitate or conceal an infringement of any right covered by this Treaty or the Berne Convention: (i) to remove or alter any electronic rights management information without authority; (ii) to distribute, import for distribution, broadcast or communicate to the public, without authority, works or copies of works knowing that electronic rights management information has been removed or altered without authority.

Article 19 of the WIPO Performances and Phonograms Treaty, 1996 (WPPT) contains nearly identical language. According to Article 19(2) of WPPT "rights management information" means information which identifies the performer, the performance of the performer, the producer of the phonogram, the phonogram, the owner of any right in the performance or phonogram, or information about

\footnotetext{
${ }^{25}$ See Article 10 read; "It is understood that the provisions of Article 10 permits Contracting Parties to carry forward and appropriately extend in to the digital environment limitations and exception in their national laws which have been considered acceptable under the Berne Convention. Similarly these provisions should be understood permit Contracting Parties to devise new exceptions and limitation that are appropriate in the digital network environment". It is also understood that Article 10(2) neither reduces not extends the scope of applicability of the limitation and exceptions permitted by the Berne Convention".

${ }^{26}$ Article 11 read: "Contracting Parties shall provide adequate legal production and effective legal remedies against the circumvention of effective technological measures that are used by authors in connection with the exercise of their rights under this treaty or the Berne Convention and that restrict acts, in respect of their works. Which are not authorized by the authors concerned or permitted by law."

${ }^{27}$ See Article 12
}

the terms and conditions of use of the performance or phonogram, and any numbers or codes that represent such information, when any of these items of information is attached to a copy of a fixed performance or a phonogram or appears in connection with the communication or making available of a fixed performance or a phonogram to the public. The workings of these provisions give sufficient flexibility to introduce appropriate provisions keeping in mind the interest of the users, manufactures of technology and that of the owners of work. ${ }^{28}$

\section{United states digital act}

The appropriate application of the reproduction right in the case of temporary copies in computer random access memory continues to be a subject of debate world over. Hence, the Digital Millennium Copyright Act, $1998^{29}$ (DMCA) was enacted in the United States to supplement the copyright law that implements two treaties of the World Intellectual Property Organization (WIPO).These treaties are: the WIPO Copyright Treaty, 1996 and the WIPO Performances and Phonograms Treaty, 1996. It criminalizes production and dissemination of technology, devices, or services intended to circumvent measures (commonly known as digital rights management or DRM) that control access to copyrighted works. It also criminalizes the act of circumventing an access control, whether or not there is actual infringement of copyright itself. In addition, the DMCA heightens the penalties for copyright infringement on the Internet. The DMCA is divided into five titles:

I. Title I, the "WIPO Copyright and Performances and Phonograms Treaties Implementation Act of 1998," implements the WIPO treaties.

II. Title II, the "Online Copyright Infringement Liability Limitation Act," creates limitations on the liability of online service providers for copyright infringement when engaging in certain types of activities. The Title two of the DMCA addresses the issue of Internet service providers (ISPs) responsibility for copyright infringement committed by their subscribers. The DMCA says that ISPs are not responsible for the actions of their clients as long they meet a number of provisions. They first have to meet one of the four definitions of an ISP as set out by the DMCA. Each of the four types have a different set of provisions the ISP must comply with. They then have to inform their users of and carry out a policy which says that people caught using their service for infringement multiple times will have their subscriptions to the service cancelled. Finally, this section of the DMCA gives the copyright holder a new right to call upon the courts to subpoena an ISP for the identification of an alleged copyright infringer.

III. Title III, the "Computer Maintenance Competition Assurance Act," creates an exemption for making a copy of a computer program by activating a computer for purposes of maintenance or repair.

${ }^{28}$ For detail discussion see David Bainbridge, Intellectual Property, Person Education (Singapore Ptc. Ltd., 2003); W. R. Cornish, Intellectual Property: Cases and Materials (Sweet and Maxwell, London, 1999); W.R. Cornish, Intellectual Property (Sweet and Maxwell, London, 1996); Holyook and Torremans, Intellectual Property Law (Butterworths, London, 1995); David I. Brainbridge, Intellectual Property Law: Cases and Materials (Pitman Publishing, London, 1995).

${ }^{29}$ Pub. L. No. 105-304, 112 Stat. 2860 (Oct. 28, 1998). See Super Cassetes Industries Ltd. v. Myspace Inc., MIPR 2011 (2) 303: 2011 (48) PTC 49 (Del). 
IV. Title IV contains six miscellaneous provisions, relating to the functions of the Copyright Office, distance education, the exceptions in the Copyright Act for libraries and for making ephemeral recordings, "webcasting" of sound recordings on the Internet, and the applicability of collective bargaining agreement obligations in the case of transfers of rights in motion pictures.

V. Title V, the "Vessel Hull Design Protection Act," creates a new form of protection for the design of vessel hulls.

Several judicial decisions of the United States Courts have discussed a large number of issues on protection of right of reproduction in Internet. In July 2002, Edelman v. $\mathrm{N}_{2} \mathrm{H}^{30}$ American Civil Liberties Union filed a suit on the behalf of Benjamin Edelman, a computer researcher at Berkman Centre for Internet and Society, seeking a declaratory judgment to affirm his first amendment rights when reverse engineering the censor ware product of defendant $\mathrm{N} 2 \mathrm{H} 2$ in case he intended to publish the finding. N2H2 filed a motion to dismiss, which the court granted. In Real Networks, Inc. v. DVD Copy Control Association, Inc., ${ }^{31}$ the DVD Copy Control Association won a suit against Real Networks for violating copyright law in selling its Real DVD software, allowing users to copy DVDs and store them on a hard drive. The DVD Copy Control Association claimed that Real violated the Digital Millennium Copyright Act by circumventing anti-piracy measures ARccOS Protection and Rip Guard, as well as breaking Real's licensing agreement with the MPAA's Content Scrambling System. The United States District Court concluded that Real Networks violated the anti-circumvention and anti-trafficking provisions of the Digital Millennium Copyright Act when the DVD copying software Real DVD bypasses the copy protection technologies of DVD.

In Viacom Inc. v. YouTube, Google Inc., ${ }^{32}$ Viacom sued YouTube, a video-sharing site owned by Google, alleging that YouTube had engaged in "brazen" and "massive" copyright infringement by allowing users to upload and view hundreds of thousands of videos owned by Viacom without permission.-A motion for summary judgement seeking dismissal was filed by Google and was granted in 2010 on the grounds that the Digital Millennium Copyright Act's "safe harbour" provisions shielded Google from Viacom's copyright infringement claims. In 2012, on appeal to the United States Court of Appeals for the Second Circuit, it was overturned in part. On April 18, 2013, District Judge Stanton again granted summary judgment in favour of defendant YouTube. In IO Group, Inc. v. Veoh Networks, Inc., ${ }^{33}$ IO Group, Inc. on June 23, 2006 filed a complaint against Veoh Networks, Inc. in the United States District Court for California's Northern District. IO Group alleged that Veoh was responsible for copyright infringement by allowing videos owned by IO Group to be accessed through Veoh's online service without permission over 40,000 times between the dates June 1 and June 22. Veoh is a Flash video site relying on user contributed content. IO Group argued that since Veoh transcoded user uploaded videos to Flash format it became a direct infringer and the materials were under their direct control, thereby disqualifying them for the Digital Millennium Copyright Act safe harbor protection. The ruling judge disagreed with the argument, stating that "Veoh has simply established a system whereby software automatically processes user-submitted content and recasts it in a

\footnotetext{
${ }^{30}$ Civil Action No. 02-CV-11503-RGS (2003).

${ }^{31} 641$ F. Supp. 2d 913 (2009).

${ }^{32}$ No. 07 Civ. 2103.

33586 F. Supp. 2d 1132 (N.D. Cal. 2008).
}

format that is readily accessible to its users. Veoh preselects the software parameters for the process from a range of default values set by the third party software... But Veoh does not itself actively participate or supervise the uploading of files. Nor does it preview or select the files before the upload is completed. Instead, video files are uploaded through an automated process which is initiated entirely at the volition of Veoh's users." The Court has granted the Veoh's motion for summary judgment, on the basis of the Digital Millennium Copyright Act, holding that the defendant's video-sharing web site complied and was entitled to the protection of the statute's "safe harbour" provision.

In Vernor v. Autodesk, Inc. ${ }^{34}$ after numerous the Digital Millennium Copyright Act takedown notices in response to his eBay listings, Timothy S. Vernor sued Autodesk in August 2007 alleging that Autodesk abused the Digital Millennium Copyright Act and disrupted his right to sell used software he bought at a garage sale. In May 2008, a federal district judge in Washington State dismissed Autodesk's argument that the software's license agreement pre-empted the seller from his rights under the first-sale doctrine. In September 2010, the United States Court of Appeals for the Ninth Circuit reversed, holding that a software user is a licensee rather than an owner of a copy where the copyright owner (i) specifies that the user is granted a license; (ii) significantly restricts the user's ability to transfer the software; and (ii) imposes notable use restrictions. In Lenz v. Universal Music Corp., ${ }^{35}$ the United States District Court for the Northern District of California denied a motion to dismiss for failure to state a claim. Although the opinion is of limited precedential value-it was not scheduled for publication- the case has received substantial attention for its treatment of the fair use defense in the context of takedown notices under the Digital Millennium Copyright Act. Deciding the question of first impression, the court concluded that a copyright owner must determine whether a particular use is protected under fair use, in order to proceed under Section 512(c), which requires "a good faith belief that use of the material in the manner complained of is not authorized by the copyright owner, its agent, or the law." District Judge Jeremy Fogel of San Jose, California ruled that copyright holders cannot order a deletion of an online file without determining whether that posting reflected "fair use" of the copyrighted material. The court held that a failure to consider fair use prior to issuing the takedown notice was sufficient to constitute a cause of action for misrepresentation. ${ }^{36}$

In Flava Works, Inc. v. Gunter, ${ }^{37}$ the court denied the defendant safe harbour protection under Digital Millennium Copyright Act. The district court found that the defendant had knowledge of its users' infringing activity and also failed to prevent future infringing activity. As such the plaintiff's motion for preliminary injunction was granted. On appeal, however, the Seventh Circuit vacated the injunction, citing the standard set in eBay Inc. v. Merc Exchange, L.L.C. ${ }^{38}$, which states that courts should not rely on categorical rules as a standard

\section{${ }^{34} 621$ F.3d 1102 (9th Cir. 2010). \\ 35572 F. Supp. 2d 1150, 1151 (N. D. Cal. 2008).}

${ }^{36}$ For detail discussion see Ayush Sharma, "Indian Perspective of Fair Dealing under Copyright Law: Lex Lata or Lex Ferenda? " 14 Journal of Intellectual Property Rights (2009) pp. 523-531; Giuseppina D’Agostino, “Healing Fair Dealing? A Comparative Copyright Analysis of Canada's Fair Dealing to UK Fair Dealing and US Fair Use," 53 Mc Gill Law Journal (2008) pp. 309-363; Burrell Robert, "Reining in Law: Is Fair Use the Answer?", 4 Intellectual Property Quarterly (2001) pp. 361-388.

${ }^{37} 689$ F.3d 754 (7th Cir. 2012).

38547 U. S. 388 (2006). 
for injunction. In Ouellette v. Viacom International Inc., ${ }^{39}$ the court denied plaintiff's attempt to find liability for YouTube and Myspace's takedowns of the plaintiff's homemade videos. Despite potential fair use claims, the court found it impossible to use the Digital Millennium Copyright Act takedown provisions as a foundation for liability. The court found that the safe harbor provision serves "to limit the liability of Internet service providers, not to create liability that could not otherwise be imposed under existing law independent of the Digital Millennium Copyright Act. In Sony Computer Entertainment America v. George Hotz, ${ }^{40}$ Sony sued Hotz over violating the Section 1201 of the Digital Millennium Copyright Act as well as the Federal Fraud and Abuse Act due to facilitating consumers to jailbreak their Play Station 3 consoles. Hotz argued that because he had purchased the product, he had the right to do with it as he pleased. After three months, Sony and Hotz decided to settle out of court. This also included an injunction against George Hotz, barring him from hacking any more Sony products.

\section{Indian protection}

Since the time of Copyright (Amendment) Act, 1984 a number of attempts have been made to make Indian Copyright Act, 1957 in tune with the digital technology. The Indian Copyright Act was amended in a number of times to include computer programme as literary work. But the major effort took place in the Copyright (Amendment) Act, 1994. After the amendment the reproduction right of literary, dramatic or musical work includes storing of it in "any medium by electronic means". ${ }^{41}$ The new definition sound recording ${ }^{42}$ recognise recording of it in any medium. Thus, Section 2(xx) of the Copyright Act, 1957 provides: "sound recording means a recording of sounds from which such sounds may be produced regardless of the medium on which such recording is made or the method by which the sounds are produced". That will include digital medium as well. So the reproduction right recognised for these works in Section 14 will be applicable even to films and sound recordings in digital format. Only work left out is the artistic works since there is no specific mention of the right to storage of the work in the digital medium in Section 14(1)(c) similar to Section 14(1)(a)(i).

The right of making available recognised in the WCT in the context of digital technology is covered under the new definition of communication to public. According to new Section 2(ff) of the Copyright Act, 1957 "communication to the public means making any work or performance available for being seen or heard or otherwise enjoyed by the public directly or by any means of display or diffusion other than by issuing physical copies of it, whether simultaneously or at places and time chosen individually, regardless of whether any member of the public actually sees, hears or otherwise enjoys the work or performance so made available." ${ }^{43}$ The Copyright (Amendment) Act, 2012 in connection to Section 14 regarding 'meaning of copyright' provides the right of 'commercial rental' to cinematograph films and sound recordings by amending the word 'hire' to 'commercial rental' in the existing provision relating to cinematograph films [clause (d) (ii)] and sound recording [clause (e) (ii)] with identical language providing for the right 'to sell or give on commercial rental or offer for sale or for such rental, any copy of the' film or sound recording.

${ }^{39} 2012$ WL 850921 (D. Mont. April 25, 2012).

${ }^{40}$ No. CV11-0167 (N.D. Cal. Apr. 11, 2011).

${ }^{4}$ See Section 14(a) (ii) of the Copyright Act, 1957.

${ }^{42}$ Inserted by the Copyright (Amendment) Act, 1994.

${ }^{43}$ Inserted by the Copyright (Amendment) Act, 2012.
The obligation under Article 11 of the TRIPS Agreement, Article 7 of WCT and Article 9 of WPPT is to provide for 'commercial rental' rights for computer programme and cinematograph film. This right was introduced in 1994 in Section 14 using the word 'hire'. However, keeping in view the possibility of interpreting this term to include noncommercial hire and lending by libraries and educational institutions, the term 'hire' in Section 14 (b) for computer programme was replaced with the term 'commercial rental' in the 1999 Amendment. The term 'hires' in Section 14 (d) and (c) with regard to a cinematograph film and sound recording respectively, is now replaced with the term 'commercial rental'. Thus, the right of communication in Section 14 recognizes the making available of the work regardless, of whether any member of the public actually sees, hears or otherwise enjoys the work so made available. This will enable the authors of all categories of work to protect the communication of the work through Internet. The notion of publication of the work is also changed in the Act so as to enable publication through the new media. As per Section 3 of the Act, publication means making a work available to the public by issue of copies or by communicating the work to the public. This section read with the new definition of communication to public will enable the authors who publish the work through Internet satisfy the requirement of publication to enjoy the benefits under the Act.

Section 37 of the Copyright Act provides that every broadcasting organization shall have broadcast reproduction rights in respect of its broadcast. In Star India Pvt. Ltd. v. Haneeth Ujwal, ${ }^{44}$ the plaintiffs are the leading sports broadcaster in India and the exclusive licensee of media rights to various sporting events / properties. The Delhi High Court held that any hosting, streaming, making available for viewing and/or communication to the public of the "2014 India-England Series Matches", as broadcast on the plaintiffs' Channels by any means on any platform including the internet and mobile, by any of the named or unnamed defendant websites would be illegal and amount to violation of the broadcast reproduction rights of the plaintiffs protected under Section 37 of the Copyright Act, 1957. Thus both reproduction and communication to public rights are now extended to substantially all kinds of works in digital format. But the Act has not deemed storage and it is a matter of interpretation to determine whether temporary and permanent reproduction will form part of this right. If temporary reproduction is included as part of reproduction right the interest of users of digital materials and service providers of these materials will be affected. To overcome this corresponding changes are not introduced in Section 52 dealing with permitted use of works without the permission of the owner. The activities of browsing, downloading, storing of digital materials for research or personal use may be treated as reproduction and the existing fair dealing provisions in Section 52 are inadequate to protect them particularly when the materials are in multimedia. Section 52(1) (a) covers only literary, dramatic, musical or artistic work. There is no provision permitting fair dealing or personal use of cinematograph film and sound recordings.

This is true in the case of temporary reproduction made by the service providers while routing the materials. Service providers providing link facilities including deep linking will be the worst affected since their activities will constitute reproduction. There is a need to introduce specific provision in Section 52 to permit these activities. The host providers will also be affected since they provide space for the purposing of storing materials for distribution through the act. As of now they are liable if they have knowledge or reasonable

\footnotetext{
${ }^{44} 2014$ LawSuit (Del) 2711.
} 
ground to believing that the making available of the materials would be infringement of copyright ${ }^{45}$. The Information Technology Act, 2000 has in some cases added the responsibility of the service providers by mandating them to establish their innocence to escape liability ${ }^{46}$. The present provisions are inadequate to protect the interest of various kinds of service providers. In this context it is important to note that no attempt was made in 1994 to introduce new provisions to protect the fair dealing rights of the users of digital materials that too in the Internet. So is the case with the liability of service providers. In TV Independent News Service Pvt. Ltd. v. India Broadcast Live $L l c,{ }^{47}$ the court has adopted a somewhat nuanced approach, at the same time; it noticed the absence of long arm statutes or provisions, in Indian law. That Parliament cannot be attributed lack of awareness of such aspects is clear from provisions of the Information Technology Act, 2000. Sections 2(j)(k) and (1) contain definitions which are of the widest amplitude sufficient to accommodate the Internet and subsequent technologies.

The Copyright (Amendment) Act, 2012 has introduced provision relating to protect the electronic right management system and circumvention of technological measures. A new Section 65A has been introduced to provide for protection of technological measures used by a copyright owner to protect his rights on the work. Any person who circumvents an effective technological measure applied for the protecting any of the rights, with the intention of infringing such rights, shall be punishable with imprisonment which may extend to two years and shall also be liable to fine. Another new Section 65B has also been introduced to provide protection of rights management information. Sub-section (1) provides, 'Any person, who knowingly (i) removes or alters any rights management information without authority, or (ii) distributes, imports for distribution, broadcasts or communicates to the public, without authority, copies of any work, or performance knowing that electronic rights management information has been removed or altered without authority, shall be punishable with imprisonment which may extend to two years and shall also be liable to fine. The proviso to the clause states that if the rights management information has been tampered with in any work, the owner of copyright in such work may also avail of civil remedies against the persons indulging in such acts. This amendment conforms to Article 12 of WCT and Article 19 of the WPPT relating to rights management information. The 2012 amendment has introduced a definition of "Rights Management Information" under Section 2(xa) of the Copyright Act, 1957. According to Section 2(xa) "Rights Management Information" means,-

I. the title or other information identifying the work or performance;

II. the name of the author or performer;

III. the name and address of the owner of rights;

IV. terms and conditions regarding the use of the rights; and

V. Any number or code that represents the information referred to in sub-clauses (a) to (d), but does not include any device or procedure intended to identify the user.

The case of the plaintiff in Rediff.Com India Ltd. v. E-Eighteen.

\footnotetext{
${ }^{45}$ See Section 51(a) (ii).

${ }^{46}$ See Section 79 of the Information Technology Act, 2000.

${ }^{47} 145$ (2007) DLT 521.
}

Com Ltd. ${ }^{48}$ is that it is an online media company carrying on worldwide online business of providing news, communication, entertainment, stock market analysis and shopping services through the internet. The plaintiff claims that the defendant company runs the website "www.Moneycontrol.com" - a personal finance portal. In the month of May 2008, the plaintiff noticed on the internet that the defendant had been infringing the plaintiffs copyright and passing it off as its own Dial, by displaying a deceptively similar Dial-similar to that of the plaintiffs, which was titled as "Mutual Fund Meter", to promote their business through internet on its website "moneycontrol. com". The plaintiff claims that by using a deceptively similar Dial to that of the plaintiffs dial in the same line of business, i.e. imparting information relating to the capital markets, the defendant is infringing the plaintiff's copyright, as aforesaid. The plaintiff claims that it has suffered incalculable damage due to the aforesaid alleged infringement of its copyright detailed hereinabove. It was argued that the plaintiff's copyright in the literary-cum-artistic artwork as enumerated in Section 14 of the Copyright Act, 1957 has been infringing by the defendant company. Both in relation to literary and artistic works, clauses (a) and (c) of Section 14, grant the exclusive right to make any adaptation of the work in the owner of the copyright. By reference to the definition of the expression "adaptation" contained in Section 2(a) of the Act, it is claimed that the right to make adaptation only means "any use of such work involving its rearrangement or alteration".

The court held that a comparison of works of plaintiff with that of defendant, on whole, did not lead to inference or perception that two works were similar and that the dial adopted by the defendant is an, "adaptation" of the plaintiff's work, also has no merit. Adaptation is defined in Section 2(a) to mean-in relation to a literary work or an artistic work, "the conversion of the work into a dramatic work by way of performance in public or otherwise"; in relation to literary or dramatic work, the same means, "any abridgement of the work or any version of the work in which the story or action is conveyed wholly or mainly by means of pictures in a form suitable for reproduction in a book, or in a newspaper, magazine or similar periodical report". It also means-in relation to any work, "any use of such work involving its re-arrangement or alteration". The copyright of the plaintiff in respect of its work aforesaid is in its literary work, "How hot is the stock?" and the artistic work i.e. the graphic representation of the Dial. The plaintiff has not claimed, and cannot claim, that its literary work or artistic work has been converted into a dramatic work. It cannot be claimed by the plaintiff that its literary work has been abridged by the defendant. The defendant's work cannot be labelled as use of the plaintiff's work involving its re-arrangement or alteration. The plaintiff's work is not at all used by the defendant. For it to be an adaptation, falling in Section 2(a)(v) of the Act, the work of which it is claimed that an adaptation has been made, should itself be used with rearrangement or alteration.

\section{Conclusion}

Right to reproduction of the work in any material form is one of the basic rights available to a copyright owner as recognized under Section 14 of the Copyrights Act, 1957 which includes right to reproduction in Internet. To "reproduce" means to produces again; to produce a copy. It may be an exact copy or an imitation. It is the action or process of bringing again before the mind in the same form. The word "reproduction" is a term of art and is used in commercial

${ }^{48}$ MIPR 2013 (2) 333: 2013 (55) PTC 294 (Del). 
sense. Right to reproduce is not for the convenience of the user but for the purpose of distribution. ${ }^{49}$ However, Section 14 used different terminology for recognizing this right. The scope of this right also differs. While one can see the term "reproduction" is used in the case of literary, dramatic, musical and artistic works, it is the words "make any copy" and "make any sound recording" that are the terminology used in case of cinematograph film and sound recording to recognize this right. There is no definition for the words "reproduction" or "copy" used in the Act. Right to store a work in electronic medium is newly recognised economic right of an author under Copyright Act, 1957. The recent technological development like internet, DVD, CDRom etc. have enabled the libraries and publishers of newspapers and magazines and so on to store the printed work in electronic medium. A question arises whether the storing in electronic medium is legal under copyright law? The Section 14 of the Act clarifies that for the purpose of storing in electronic medium the libraries and publishers also have to obtain permission from the author. Therefore, the Copyright (Amendment) Act, 1984 amended Section 14(1)(a)(i) which provided "to reproduce the work in any material form including the storing of it in any medium by electronic means." 50

Recently, the Copyright (Amendment) Act, 2012 amended Section 52 of the Act to make the fair use defence available to all works including cinematograph films and sound recordings. The 2012 amendment replaced the words "literary, dramatic, musical or artistic work" used in Section 52(1)(a) and 52(1)(b) with the expression "any work" ${ }^{\prime \prime}$. The amendment provides that the works which are stored in an electronic medium for the purposes of fair use do not constitute infringing copies. To facilitate digitisation of libraries, a new clause (n) has been introduced to Section 52(1) identifying certain acts not to be infringement of copyright to enable the storage of a digital copy of a work if the library possesses a non digital version of it. The newly substituted clause (n) runs thus: "the storing of a work in any medium by electronic means by a non-commercial public library, for preservation if the library already possesses a non- digital copy of the work." It is remarkable to note that through the legal development of copyright law the scope of the right has been expanded and thus right of reproduction of copyright in Internet also been added to, while on the other hand the defence of the fair use has also been expanded. As a result of which ultimate protection of creative works under copyright law became complex and thus real authors are getting nothing. Seeking any relief for copyright infringement is a difficult issue in the contemporary era.

\section{Acknowledgements}

None

\section{Conflict of interest}

The author declares that there is no conflict of interest.

${ }^{49}$ State Bank of India v. Collector of Customs, (2000) 1 SCC 727: [2000] 1 SCR 137.

${ }^{50}$ Inserted by the Copyright (Amendment) Act, 1994 [w.e.f. 10. 05. 1995]

Section 7.

${ }^{51}$ Inserted by the Copyright (Amendment) Act, 2012 [w. e. f. 21. 6. 2012] Section 32(i) (a). 